\section{Dental implants in patients affected by systemic diseases}

\author{
N. Donos ${ }^{* 1}$ and E. Calciolari ${ }^{1}$
}

VERIFIABLE CPD PAPER

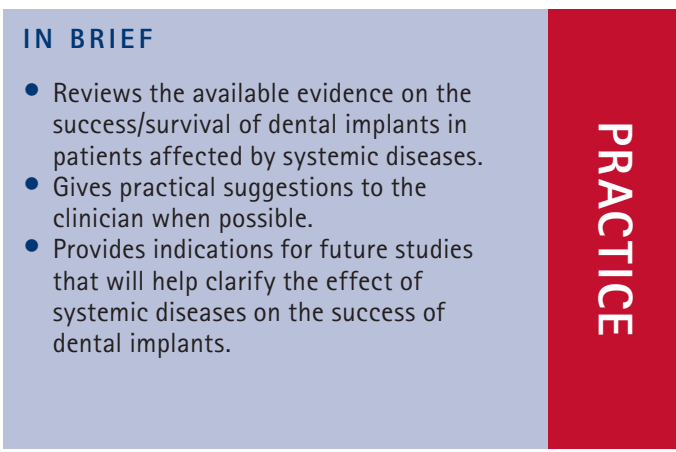

\begin{abstract}
Several systemic diseases (and relative medications) have been reported to impair or in some cases complicate dental implant surgery. In broader terms, when dealing with patients suffering from systemic diseases, the monitoring of the medical condition and of the related post-operative complications is of great importance in order to avoid risks which could jeopardise the health of the patient. In this review, the available evidence on implant survival/success, as well as relevant surgical recommendations in patients affected by systemic diseases, are evaluated and when possible, practical suggestions for the clinician are provided.
\end{abstract}

\section{INTRODUCTION}

Dental implants are a reliable and wellestablished option for the treatment of complete and partial edentulism and have been associated with high survival rates both in pristine and regenerated bone. ${ }^{1-4}$

One of the key factors for the success of implant therapy is appropriate patient selection, ${ }^{5,6}$ which indicates that, like for all surgical procedures, a thorough medical history should be carefully registered together with the assessment of the complexity of the involved surgical site. A number of systemic conditions have been reported to complicate or even contraindicate implant surgery, with different levels of evidence. ${ }^{7,8}$ Since the number of medically compromised patients requiring implant surgery is potentially increasing, understanding the effect of any systemic disease (and associated medications) on the surgical procedure and on the final treatment outcome in relation to implants is of paramount importance. This critical review aims to present a summary of the available knowledge on this topic and to provide practical guidelines for patient management.

\section{ABSOLUTE MEDICAL CONTRAINDI- CATIONS TO DENTAL IMPLANTS}

Implant surgery, like any other non-compulsory surgery, must be always carried

'UCL Eastman Dental Institute, 256 Gray's Inn Road, London, WC1X 8LD

*Correspondence to: Professor Nikos Donos

Email:n.donos@ucl.ac.uk

\section{Refereed Paper}

Accepted 8 August 2014

DOI: 10.1038/sj.bdj.2014.911

${ }^{\circ}$ British Dental Journal 2014; 217: 425-430 out within a 'safety regime.' Although the evidence from the literature is limited and mainly anecdotal, Hwang et al. described some severe systemic conditions representing an absolute contraindication for implant surgery (and any other elective surgery). ${ }^{9}$ These conditions include:

- Recent myocardial infarction or cerebrovascular accident ( $<6$ months)

- Recent valvular prosthesis placement or transplant (<6-12 months)

- High risk of bleeding (INR >3-3.5, platelet count $<50,000 / \mathrm{mm}^{3}$ )

- Significant immunosuppression (total white count $<1,500-3,000$ cells $/ \mathrm{mm}^{3}$ )

- Active cancer therapy

- Intravenous bisphosphonate treatment.

In all the aforementioned conditions, implant surgery may not only be at a higher risk of failure, but also the surgical procedure per se may jeopardise the general health of the patient and represent a life-threatening event.

In addition to the above, psychiatric disorders should also be carefully evaluated, since they may prevent the patient from properly understanding or accepting the proposed treatment and they are often associated to poor oral hygiene. ${ }^{9}$

\section{MEDICALLY COMPROMISED PATIENTS AND DENTAL IMPLANTS}

A number of animal and human studies have been performed in order to investigate the possible influence of common systemic diseases on implant survival/success. However, as highlighted by a recent review, ${ }^{8}$ the level of available evidence based on well-recognised evidence-based criteria ${ }^{10}$ is overall weak, since most of the data derive from case series or case report studies and only a limited number of RCTs have been published.

\section{BONE DISEASES}

\section{Osteoporosis}

Osteoporosis is a very common skeletal disease characterised by a reduction in bone density and alterations in the microstructure of bone that lead to an increased risk of fractures. ${ }^{11}$ Its prevalence in Europe was estimated to be 27.6 million people in 2010 , but this number is expected to rise in the next years. ${ }^{12}$ The hypothesis that the impaired bone metabolism in osteoporotic patients can impair bone healing around dental implants and affect osseointegration is biologically plausible but still controversial.

Some evidence of reduction in bone-toimplant contact (BIC) and bone volume per tissue volume (BA) has been reported at eight weeks after implant placement in osteoporotic rat tibias. ${ }^{13}$ In addition, in other preclinical studies, reduction of bone mechanical properties, ${ }^{14,15}$ formation of impaired extracellular matrix (ECM) and delay of bone healing ${ }^{16-18}$ have been shown. However, the use of implants with modified, hydrophilic surfaces treatment has shown to significantly improve dental implant success in osteoporotic animals ${ }^{19,20}$ and should be further investigated in future human studies. $^{21,22}$ Even though few prospective and retrospective clinical studies indicated that osteoporosis could impair implant success, ${ }^{5,23-25}$ a systematic and a critical review on this topic concluded that there is not 
enough evidence to consider osteoporosis as an absolute contraindication for implant placement. ${ }^{26,27}$ In clinical practice, when dealing with osteoporotic patients, a careful evaluation of bone density at the implant site should be performed. Osteoporotic bone can be regarded as equivalent to Type IV according to Lekholm and Zarb classification ${ }^{28}$ and, according to the limited available evidence, the clinician may also consider to allow a longer healing period for osseointegration before the prostheses' insertion..$^{29}$ Currently, immediate loading is not recommended and it is plausible to expect an increased risk of complications in case bone augmentation procedures are required. ${ }^{30-32}$

\section{Medications-related osteonecrosis of the jaws (MRONJ)}

A potential issue in osteoporotic patients is the possibility that antiresorptive medications, like bisphosphonates (BP) or denosumab, may interfere with bone turnover at the dental implant interface, reducing implant success and increasing the risk of developing osteonecrosis of the jaws (ONJ). ${ }^{33,34} \mathrm{BP}$ can be administered either orally (mainly for osteoporosis) or intravenously (mainly for multiple myeloma or other malignant diseases) and have a potent inhibitor effect on osteoclast cells. Denosumab is an antibody against RANK ligand (RANK-L) and therefore inhibits osteoclast function.

Only a few studies have been published on the risk of MRONJ subsequent to dental implant placement, but it is advisable to consider this risk comparable to the one associated with a tooth extraction. ${ }^{35}$ There is a general consensus on contraindicating implant surgery in cancer patients treated with intravenous $\mathrm{BP},{ }^{8}$ while a systematic review found that in patients taking oral $\mathrm{BP}$ for less than five years, neither the shortterm (1-4 years) survival of dental implants nor the risk of ONJ seem to be increased. ${ }^{36}$ The current evidence shows that the risk of ONJ seems to be higher for intravenous $\mathrm{BP}$ than oral BP, but it increases with the duration of the therapy. ${ }^{37}$ According to Lazarovici et al., ${ }^{38}$ on average ONJ develops 68 months, 16 months and 50 months after implant surgery in patients in therapy with alendronate (os), zoledronic acid (iv) and pamidornate (iv), respectively. In this study, six out of 27 patients developed ONJ within six months from dental implant placement and therefore it was suggested that some cases of ONJ might not be triggered by the surgical trauma caused by implant placement. Furthermore, according to Jacobsen et al.,$^{34}$ a higher risk of ONJ may be expected after implant placement in the posterior areas of both jaws.
In conclusion, oral BP are not considered a contraindication for implant surgery, but it is important to explain in details the possible risk of complications to the patients. It has been suggested that in order to promote improved implant outcomes and reduce the risk of $0 N J$, the clinician should reduce the surgical trauma as much as possible, use antibiotic prophylaxis and topical antiseptics. ${ }^{39}$ Although there are only limited data on the efficacy of a drug holiday from BP before oral surgical procedures in general, the clinician may consider to discontinue BP two months before and three months after surgery in patients taking this medication for more than four years and also in patients taking BP associated with corticosteroids or anti-angiogenic medications..$^{35,40}$ The benefits of stopping treatment with denosumab before implant placement have not been evaluated, although it has been reported that most of the anti-resorptive effect of denosumab disappears within six months. ${ }^{35}$

\section{RHEUMATOID ARTHRITIS AND OTHER LESS COMMON BONE DISEASES}

A very limited number of studies have evaluated the effect of other bone diseases on dental implant outcomes. A few case reports reported successful implant treatment in patients with osteogenesis imperfecta ${ }^{41-45}$ and ankylosing spondylitis. ${ }^{46}$ In a patient affected by osteoporosis and polyarthritis, Eder et $a l .{ }^{47}$ reported a peri-implant bone resorption of $1.38 \mathrm{~mm}$ at four years, slightly greater than expected in a healthy subject.

Both case reports ${ }^{48}$ and retrospective case series ${ }^{49}$ have shown a high success of implants placed in patients with rheumatoid arthritis, however, an increased bone resorption and bleeding can be expected in patients with concomitant connective tissue diseases. ${ }^{50}$

\section{DIABETES MELLITUS}

Diabetes mellitus comprises a group of metabolic diseases characterised by hyperglycaemia, as a result of a reduced secretion and/or an impaired action of insulin. Its global prevalence was estimated to be $2.8 \%$ in 2000 and is expected to rise to $4.4 \%$ in $2030 .^{51}$ Type 1 diabetes is an autoimmune disease associated to pancreatic $\beta$-cell destruction and therefore requires insulin therapy, while type 2 diabetes is characterised by a relative rather than absolute insulin deficiency and is usually a multi-factorial disease. It has been extensively demonstrated that hyperglycaemia has a negative effect on bone metabolism, usually referred to as diabetic 'osteopathy'. In particular, it has been associated to reduced bone mineral density, increased risk of fractures, reduced bone mechanical properties, impaired endochondral and intramembranous bone formation and impaired microarchitectural quality of bone (for review Retzepi and Donos ${ }^{52}$ ). Taking all this into consideration, it may be plausible to suggest that diabetes mellitus may impair osseointegration and implant related outcomes. Preclinical studies have shown a negative effect of hyperglycaemia on BIC and implant osseointegration and at the same time have highlighted the importance of glycaemic control. ${ }^{53-55}$ The evidence from prospective and retrospective studies supports a positive survival rates of dental implants placed in diabetic patients with good/fair metabolic control, ranging from 85.5 to $100 \% .{ }^{56}$ Some studies demonstrated higher percentages of early implant failure in diabetic patients compared to late failures ${ }^{57-59}$ and an increased risk of periimplantitis. ${ }^{60}$ Although poor metabolic control has been associated to higher implant failures ${ }^{61}$, a recent review by Oates et al. ${ }^{62}$ found that the evidence on the impact of poor metabolic control is still limited. In fact, most of the retrieved studies did not clearly report glycaemic control, which should be assessed through the measurement of glycated haemoglobin HbA1c (53), and they found only two prospective cohort studies and one prospective case series meeting this requirement. In two of these publications, no implant failure was registered over a fourmonth evaluation period before restoration ${ }^{63}$ and after one year of restoration respectively. ${ }^{64}$ The third study involved 45 diabetic patients, with 44 of them having HbA1c levels up to 9\% (22 well controlled and 22 fairly well controlled) and only one patient with levels over 9\% (poorly controlled) and reported a failure rate of $9.1 \%$ in poorly controlled diabetic patients along a mean evaluation period of 42.4 months. ${ }^{65}$ When combining the fairly well controlled and the poorly controlled patients, the cumulative implant failure rate was 3.9\%. The authors concluded that implant therapy could be beneficial even in patients with poor glycaemic control, with appropriate accommodations for delays in osseointegration.

However, it is also important to emphasise that hyperglycaemia may lead to severe complications like macro/micro angiopathy, neuropathy and increased risk of infections, thus a strict glycaemic control before and after implant treatment is highly recommended. ${ }^{8,66,67}$ When dealing with diabetic patients, the clinician should consider antibiotic prophylaxis as appropriate and the use of antiseptics pre- and post-operatively to reduce the potential risk of infections. ${ }^{7,53,66}$ In addition, these patients should be invited/ 
counselled to quit smoking and placed in a strict regimen of supportive therapy and maintenance/recall systems in order to optimise the control of oral hygiene and reduce the risk of periodontal and peri-implant infections. ${ }^{68}$

\section{CARDIOVASCULAR DISEASES (CVDs)}

The hypothesis of a higher risk of failures in patients with cardiovascular diseases is related to the possibility that the impaired blood supply and the consequent hypoxia may negatively affect the healing process of bone around implants. ${ }^{69}$ However, several retrospective studies did not show different implant related clinical outcomes in patients with or without CVDs. ${ }^{5,70,71}$

In this type of patients, Taguchi et al. ${ }^{72}$ suggested sedation with midazolam and propofol before implant surgery, in order to better stabilise haemodynamics and reduce the stress. Since CVDs include a wide spectrum of pathologies with different levels of severity, it is always important for the dentist to consider issues related to the medical condition of the patient before starting any kind of treatment, especially because patients with CVDs may experience increased bleeding, high blood pressure or even ischaemic attacks during implant surgery. ${ }^{8}$ A careful monitoring of these patients and a systematic update of their medication intake is always highly recommended. Whenever indicated and with liaison with the cardiologists, antibiotic prophylaxis may be needed for infective endocarditis prevention. ${ }^{73}$

\section{BLEEDING DISORDERS}

Inherited bleeding disorders may increase the risk of haemorrhage during implant surgery, but there is no evidence suggesting that they are a contraindication for implant survival/success. The most common inherited bleeding disorder is von Willebrand's disease, that has an estimated prevalence of $1-2 \%$, while haemophilia A occurs in one in 5,000 live male births and haemophilia B occurs in one in $30,000 .^{74,75}$ In patients with inherited bleeding disorders, any elective surgery should be carefully planned and discussed with the haemophilia centre. The following guidelines have been proposed: ${ }^{76,77}$

- Augmentation of the coagulation factor before surgery (and before nerve block). It is recommended that for invasive procedures the coagulation factor reaches a minimum level of 50\%

- Peri- and post-operative use of antifibrinolytic agents (oral tranexamic acid and/or 5\% tranexamic mouthwash). These should be continued up to seven days post-surgery
- Use local anaesthesia with vasoconstrictor, which should be performed with the slow injection technique and with fine gauge needles

- Use appropriate suturing technique

- Avoid sinus lift and bone grafts

- In order to reduce the risk of local infection and inflammation the clinician is recommended to use topical antiseptics (chlorhexidine or povidone iodine), or antibiotics if the infection is considered to require more than topical measures

- Discuss the use of non-steroidal antiinflammatory medications with the haemophilia centre, since they may increase the risk of bleeding.

Patients taking anticoagulant (like warfarin) or antiplatelet agents are also at higher risk of haemorrhage during implant surgery. It has been suggested that discontinuing oral anticoagulant therapy (OAT) significantly increases the risk of thromboembolic events and that bridging it with heparin or reducing the dosage may not reduce the risk of thromboembolic events. ${ }^{78}$ According to a systematic review of Madrid and Sanz, ${ }^{78}$ for minor oral surgery procedures OAT should not be modified, since results from RCTs and CCTs demonstrated that OAT patients (INR 2-4) who did not discontinue their medication did not have a risk of post-operative bleeding higher than those who discontinued the medication. RCTs comparing different haemostatic agents (tranexamic acid mouthrinses, gelatine sponges and fibrin glue) have shown similar results. It is also important to remember that several medications commonly used by dental practitioners (like metronidazole, erythromycin, clarithromycin) may increase the anticoagulant effect of warfarin. ${ }^{79-83}$

\section{MUCOSAL DISEASES}

\section{Oral lichen planus (OLP)}

OLP is a chronic inflammatory disease, with a prevalence between 0.5 to $2 \%$, that can affect the mucous membranes of the oral cavity, with papular/reticular lesions. ${ }^{84,85}$ A few case reports have been published on the use of dental implants in patients affected by OLP, but they all reported positive results, with $100 \%$ success rate at 21-36 month follow-up. ${ }^{86,87}$ In a retrospective study, Czerninski et al. ${ }^{88}$ did not find a different success rate of implants placed in 14 patients with OLP and in 15 patients without OLP, however Hernandez et al. ${ }^{89}$ reported a higher rate of peri-implant mucositis (44.6\% of implants) and peri-implantitis (10.7\% of implants) in 18 patients affected by OLP that were rehabilitated with 56 implants. Furthermore, it seemed that desquamative gingivitis may be more frequently associated to peri-implant mucositis. Considering the risk, although rare $(1 \%),{ }^{90}$ of malignant transformation of OLP lesions, a longterm monitoring of these patients is highly recommended.

\section{Ectodermal dysplasia}

Ectodermal dysplasia comprises a heterogeneous group of genetic disorders with an incidence of one every 100,000 births. ${ }^{91}$ It affects ectodermal structures and is associated to hypo/anodontia on both milk and permanent dentitions, impacted teeth, variations in size and shape of teeth, mineralisation disturbances, multiple diastemas and under-developed alveolar ridges. ${ }^{92}$ Dental implants have been proposed as an effective treatment both in adults and children affected by this disease. ${ }^{93}$ A review of Yap et al..$^{94}$ reported implant survival rates of 88.5-97.6\% and a failure rate at subject level of 16.7-35.7\%, with a higher incidence in the upper jaw. Recently, in a consensus paper, it was highlighted that the rehabilitation of children with ectodermal dysplasia needs a multidisciplinary approach and a careful pre-treatment oro-facial assessment. ${ }^{95}$ No consensus was reached in relation to the most appropriate age for implant surgery, but the experts agreed that at 7-8 years old dental implants could be placed in the anterior mandible. If there are teeth adjacent to the edentulous area, the dentist needs to wait until growth is completed before placing implants, while if there are no adjacent teeth, the surgery can be performed earlier, but it is likely that the patient will require maxillary advancement once growth is completed. ${ }^{95}$

A few case reports have documented successful dental implant treatment in patients with Papillon Lefevre syndrome, a rare autosomal recessive form of ectodermal dysplasia associated with severe and early onset periodontitis. ${ }^{96-98}$

\section{Epidermolysis bullosa}

This defines a group of hereditary diseases of the skin and mucosal membranes characterised by the development of blisters and vesicles as a consequence of minimum trauma. It is estimated to affect approximately eight people per one million population. ${ }^{99}$ In these subjects, tooth/implant-supported prostheses are better tolerated then removable dentures, which can easily cause mucosal irritation and blisters. ${ }^{100}$ In a recent review, Feijoo et al. ${ }^{101}$ reported a success rate (\% of cases) of 97.7-100\% of dental implants in patients with epidermolysis bullosa. Although dental implants may be performed 
successfully, the clinician must be aware of the possible complications, such as the development of bleeding blisters due to the surgical trauma. ${ }^{100,102}$ In order to reduce the incidence of these unpleasant complications, implant surgery should be performed in an atraumatic way, trying for example to limit irrigation and suction, using small-sized instruments, carefully handling the soft tissues and lubricating the buccal mucosa. ${ }^{101}$ Microstomia, often associated to this disease, may limit the access to the oral cavity and prevent the use of implants in the posterior area. ${ }^{100,102-105}$

\section{HEAD AND NECK CANCER PATIENTS}

Neck and head cancers are often aggressive and may require mutilating resective surgeries, which result in evident bone defects and edentulous areas that are extremely challenging to rehabilitate. The use of bone grafts and implant-based prostheses are often the only/best way to rehabilitate these patients. ${ }^{106}$ Radiotherapy, which is performed in $60-80 \%$ of the patients affected by head and neck cancer, ${ }^{107}$ reduces cellular and vascular growth and therefore may significantly impair osseointegration of dental implants and increase the risk of complications (for example, osteoradionecrosis). ${ }^{108,109}$ Both animal and human studies have shown an increased risk of implant failure (up to 12 times) in irradiated patients. ${ }^{110}$ In a recent systematic review, Chambrone et al. ${ }^{111}$ reported a mean implant survival rate ranging from 46.3 to $98 \%$ and an increased implant failure risk (RR 2.74) in irradiated patients, in particular in the maxilla (RR 5.96). Radiotherapy seems to have both early and late effects; the early effects affect mainly salivary glands, skin and oral mucosa, while the late effects involve bone changes and may lead to demineralisation, fibrosis, increased susceptibility to infection and avascular necrosis. ${ }^{109}$ Several studies reported that hyperbaric oxygen therapy (HBOT) could significantly increase implant success and reduce unpleasant complications like osteoradionecrosis. ${ }^{107,112-114}$ However, two recent systematic reviews found that there is no evidence that HBOT can reduce implant failure and that better designed studies are needed to clarify the real benefit of HBOT on the survival rates of implants in irradiated jaws. ${ }^{11,115}$ In order to increase the implant success in these patients, a few precautions have been suggested, ${ }^{8,116}$ such as antimicrobial prophylaxis and strict surgical asepsis, and it has been recommended to wait nine months after radiotherapy before performing implant surgery. The total radiation dose should be kept under 50 Gy to reduce the risk of osseointegration failure, but in case of higher doses, the clinician may consider to use HBOT. ${ }^{116}$ A few case series reported no negative effect of chemotherapy on dental implant success. ${ }^{117,118}$

\section{AIDS AND IMMUNOCOMPROMISED PATIENTS}

A good immune response is important for wound healing, therefore it is reasonable to speculate that immunocompromised patients may be at higher risk of implant failure. The available literature on implant success in HIV positive patients is limited, however dental implants have been associated to positive short-term outcomes in these patients ${ }^{119-122}$ and Strietzel et al. ${ }^{123}$ concluded that no modification of routine dental treatment should be done, provided the immune status is stable. In a pilot study, Oliveira et al. ${ }^{124}$ compared the 12-month implant success in $25 \mathrm{HIV}$ positive patients treated with different anti-retroviral regimens and they obtained positive outcomes regardless the therapy, the CD4 T cell count and the viral load levels. However, the long-term predictability of dental implants in HIV positive patients has not been clarified yet and it is considered prudent to carry out implant surgery only when CD4 rates are high and when patients are on anti-retroviral therapy. ${ }^{8}$ No specific cut-off for CD4 cells has been proposed to preclude surgery, however when their level is under 400 cells $/ \mathrm{mm},{ }^{3}$ the risk of infections, especially from Candida, is significantly increased. ${ }^{9}$

Similar consideration and attention should be given to all patients taking immunosuppressants, for example for a transplant. Although some animal studies have shown that cyclosporine causes impairment in bone quality and bone healing around implants and in their mechanical retention, ${ }^{125-128}$ case series and case reports have documented successful implant rehabilitations in patients that underwent organ transplantation. ${ }^{129-131}$

In conclusion, no evidence exists that immunodeficiency is a contraindication for dental implants, however the medical condition should be investigated and the clinician should consider antibiotic prophylaxis and topic antiseptics (chlorexidine) to reduce the risk of infections, following communication with the relevant physician.

\section{SJÖGREN'S SYNDROME}

Sjögren's syndrome is an autoimmune disease affecting the function of exocrine glands, including salivary glands. The consequent xerostomia creates difficulties in swallowing and possible taste alterations and therefore should be taken into serious consideration by clinicians for any kind of dental treatment, including dental implants.
Due to the difficulties of these patients in wearing removable dentures, implant-based rehabilitation may be considered as the treatment of choice. Electro-stimulating devices reported positive outcomes in the management of xerostomia and Ami et $a l .{ }^{132}$ published a successful case report of an electrostimulating device fixed on a dental implant. A few studies investigated the long-term success of dental implants in patients with Sjögren's syndrome, reporting a success of $88.4-100 \%$ at 2-13 years. ${ }^{133-135}$ Although there is no evident contraindication to implant surgery in these patients, the severity of the medical condition should be carefully considered, especially in secondary forms associated with rheumatoid arthritis, where limitations of movements and manual skills may reduce the efficacy of oral hygiene procedures. $^{93}$

\section{GENERAL CLINICAL RECOMMEN- DATIONS AND CONCLUSIONS}

The evidence on the effect of systemic diseases on dental implant success is limited. This does not mean that systemic factors do not play a role in the success of dental implant treatments, but that future larger prospective studies should be carried out to improve the available knowledge and provide more robust evidence. Only a few severe conditions have been indicated as absolute contraindications for implants (and for elective surgeries in general), however this should not be perceived that in less 'life-threatening' conditions the dentist can consider dental implants as a riskfree procedure. The clinician must always balance the advantages and disadvantages of the surgical procedures and treatment modalities, communicate with the relevant physician/ specialist, and take into consideration that in some occasions non-surgical options can be equally well tolerated/accepted, with fewer chances of complications. When dealing with systemic diseases that can potentially reduce dental implant related outcomes and the healing potential of the patients, it is also important to identify and address modifiable risk factors for implant failure (such as, smoking, poor oral hygiene) and adopt more strict follow-up regimens.

1. Lambert F E, Weber H P, Susarla S M, Belser U C, Gallucci $G$ O. Descriptive analysis of implant and prosthodontic survival rates with fixed implantsupported rehabilitations in the edentulous maxilla. J Periodontol 2009; 80: 1220-1230.

2. Clementini M, Morlupi $A$, Canullo L, Agrestini C, Barlattani A. Success rate of dental implants inserted in horizontal and vertical guided bone regenerated areas: a systematic review. Int J Oral Maxillofac Surg 2012; 41: 847-852.

3. Retzepi M, Donos N. Guided Bone Regeneration: biological principle and therapeutic applications. Clin Oral Imp/ Res 2010; 21: 567-576.

4. Donos N, Mardas N, Chadha V. Clinical outcomes of implants following lateral bone augmentation: 
systematic assessment of available options (barrier membranes, bone grafts, split osteotomy). J Clin Periodontol. 2008; 35(8 suppl): 173-202.

5. Alsaadi G, Quirynen M, Komarek A, van Steenberghe D. Impact of local and systemic factors on the incidence of oral implant failures, up to abutment connection. J Clin Periodontol 2007; 34: 610-617.

6. Liddelow G, Klineberg I. Patient-related risk factors for implant therapy. A critique of pertinent literature. Aust Dent J 2011; 56: 417-426.

7. Beikler T, Flemmig T F. Implants in the medically compromised patient. Crit Rev Oral Biol Med. 2003; 14: 305-316.

8. Diz P, Scully C, Sanz M. Dental implants in the medically compromised patient. J Dent 2013; 41: 195-206.

9. Hwang D, Wang H L. Medical contraindications to implant therapy: part I: absolute contraindications. Implant Dent 2006; 15: 353-360.

10. Levels of Evidence Working Group. The Oxford 2009 Levels of Evidence. 2009.

11. Kanis J A, McCloskey E V J Johansson $\mathrm{H}$ et al. European guidance for the diagnosis and management of osteoporosis in postmenopausal women. Osteoporos Int. 2013; 24: 23-57.

12. Hernlund $E_{1}$ Svedbom $A$, Ivergard $M$ et al. Osteoporosis in the European Union: medical management, epidemiology and economic burden. A report prepared in collaboration with the International Osteoporosis Foundation (IOF) and the European Federation of Pharmaceutical Industry Associations (EFPIA). Arch Osteoporos 2013; 8: 136.

13. Glösel B, Kuchler U, Watzek G, Gruber R. Review of dental implant rat research models simulating osteoporosis or diabetes. Int J Oral Maxillofac Implants 2010: 25: 516-524.

14. Carvalho C M, Carvalho L F, Costa L J, Sa M J, Figueiredo C R, Azevedo A S. Titanium implants: a removal torque study in osteopenic rabbits. Indian J Dent Res 2010; 21: 349-352.

15. Giro G, Sakakura C E, Goncalves D, Pereira R M,

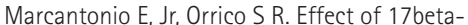
estradiol and alendronate on the removal torque of osseointegrated titanium implants in ovariectomized rats. J Periodonto/ 2007; 78: 1316-1321.

16. Keller J C, Stewart M, Roehm M, Schneider G B. Osteoporosis-like bone conditions affect osseointegration of implants. Int J Oral Maxillofac Implants 2004; 19: 687-694.

17. Mori $H$, Manabe $M$, Kurachi $Y$, Nagumo $M$. Osseointegration of dental implants in rabbit bone with low mineral density. J Oral Maxillofac Surg. 1997: 55: 351-361, 362

18. Fini M, Giavaresi G, Rimondini L, Giardino R. Titanium alloy osseointegration in cancellous and cortical bone of ovariectomized animals: histomorphometric and bone hardness measurements. Int Oral Maxillofac Implants 2002; 17: 28-37.

19. Alghamdi H S, Jansen J A. Bone regeneration associated with nontherapeutic and therapeutic surface coatings for dental implants in osteoporosis. Tissue Eng Part B Rev 2013; 19: 233-253.

20. Mardas N, Schwarz F, Petrie A, Hakimi AR, Donos $N$. The effect of SLActive surface in guided bone formation in osteoporotic-like conditions. Clin Oral Implants Res 2011; 22: 406-415.

21. Donos N, Hamlet S, Lang N P et al. Gene expression profile of osseointegration of a hydrophilic compared with a hydrophobic microrough implant surface. Clin Oral Implants Res 2011: 22: 365-372.

22. Ivanovski S, Hamlet S, Salvi G E et al. Transcriptional profiling of osseointegration in humans. Clin Oral Implants Res 2011; 22: 373-381.

23. von Wowern N, Gotfredsen K. Implant-supported overdentures, a prevention of bone loss in edentulous mandibles? A 5-year follow-up study. Clin Oral Implants Res 2001; 12: 19-25.

24. August $M$, Chung $K$, Chang $Y$, Glowacki J. Influence of estrogen status on endosseous implant osseointegration. J Oral Maxillofac Surg 2001; 59: 1285-1289, 1290-1291.

25. Blomqvist J $E$, Alberius $P$, Isaksson $S$, Linde $A$, Hansson B G. Factors in implant integration failure after bone grafting: an osteometric and endocrinologic matched analysis. Int J Oral Maxillofac Surg 1996; 25: 63-68.
26. Slagter K W, Raghoebar G M, Vissink A. Osteoporosis and edentulous jaws. Int J Prosthodont 2008; 21: 19-26.

27. Tsolaki I N, Madianos P N, Vrotsos J A. Outcomes of dental implants in osteoporotic patients. A literature review. J Prosthodont 2009; 18: 309-323.

28. Lekholm U, Zarb G, Albrektsson T. Patient selection and preparation. Tissue integrated prostheses. pp 199209. Chicago: Quintessence Publishing Co, 1985

29. Gaetti-Jardim E C, Santiago-Junior J F, Goiato M C Pellizer E P, Magro-Filho O, Jardim Junior E G. Dental implants in patients with osteoporosis: a clinical reality? J Craniofac Surg 2011; 22: 1111-1113.

30. Blomqvist J $E_{1}$ Alberius $P_{1}$ Isaksson $S$, Linde $A$ Hansson B G. Factors in implant integration failure after bone grafting: an osteometric and endocrinologic matched analysis. Int J Oral Maxillofac Surg 1996; 25: 63-68.

31. Toffler M. Osteotome-mediated sinus floor elevation: a clinical report. Int J Oral Maxillofac Implants 2004: 19: 266-273.

32. Schliephake $H$, Neukam F W, Wichmann M. Survival analysis of endosseous implants in bone grafts used for the treatment of severe alveolar ridge atrophy. J Oral Maxillofac Surg 1997; 55: 1227-1233.

33. Javed $F_{1}$ Almas K. Osseointegration of dental implants in patients undergoing bisphosphonate treatment: a literature review. J Periodonto/ 2010; 81: 479-484.

34. Jacobsen $C$, Metzler P, Rossle M, Obwegeser J, Zemann W, Gratz K W. Osteopathology induced by bisphosphonates and dental implants: clinical observations. Clin Oral Investig 2013: 17: 167-175.

35. Ruggiero S L, Dodson T B, Fantasia J et al. Medication-related osteonecrosis of the jaw. 2014 update. American Association of Oral and Maxillofacial Surgeons Position Paper, 2014.

36. Madrid C, Sanz M. What impact do systemically administrated bisphosphonates have on oral implant therapy? A systematic review. Clin Oral Implants Res 2009; 20 Suppl 4: 87-95

37. Khosla S, Burr D, Cauley J et al. Bisphosphonateassociated osteonecrosis of the jaw: report of a task force of the American Society for Bone and Mineral Research. J Bone Miner Res 2007; 22: 1479-1491.

38. Lazarovici T S, Yahalom R, Taicher S, Schwartz-Arad D, Peleg 0, Yarom N. Bisphosphonate-related osteonecrosis of the jaw associated with dental implants. J Oral Maxillofac Surg 2010; 68: 790-796.

39. Hellstein J, Adler R, Edwards B et al. Managing the care of patients receiving antiresorptive therapy for prevention and treatment of osteoporosis. Recommendations from the American Dental Assocaition Council on Scientific Affairs, 2011.

40. Damm D D, Jones D M. Bisphosphonate-related osteonecrosis of the jaws: a potential alternative to drug holidays. Gen Dent 2013; 61: 33-38.

41. Lee CY, Ertel S K. Bone graft augmentation and dental implant treatment in a patient with osteogenesis imperfecta: review of the literature with a case report. Implant Dent 2003; 12: 291-295.

42. Prabhu N, Duckmanton N, Stevenson A R, Cameron A. The placement of osseointegrated dental implants in a patient with type IV B osteogenesis imperfecta: a 9-year follow-up. Oral Surg Oral Med Oral Pathol Oral Radiol Endod 2007: 103: 349-354

43. Payne M A, Postlethwaite K R, Smith D G, Nohl F S Implant-supported rehabilitation of an edentate patient with osteogenesis imperfecta: a case report Int J Oral Maxillofac Implants 2008: 23: 947-952.

44. Binger T, Rucker $M$, Spitzer W J. Dentofacial rehabilitation by osteodistraction, augmentation and implantation despite osteogenesis imperfecta. Int $J$ Oral Maxillofac Surg 2006; 35: 559-562.

45. Wannfors K, Johansson C, Donath K. Augmentation of the mandible via a 'tent-pole' procedure and implant treatment in a patient with type III osteogenesis imperfecta: clinical and histologic considerations. Int J Oral Maxillofac Implants 2009 24: 1144-1148.

46. Barker D, Nohl F S, Postlethwaite K R, Smith D G. Case report of multiple implant failure in a patient with ankylosing spondylitis. Eur J Prosthodont Restor Dent 2008; 16: 20-23.

47. Eder A, Watzek G. Treatment of a patient with severe osteoporosis and chronic polyarthritis with fixed implant-supported prosthesis: a case report. Int J Oral Maxillofac Implants 1999; 14: 587-590.

48. Ella B, Lasserre J F, Blanchard J P, Fricain JC. A 4year follow-up of two complete mandibular implantsupported removable prostheses in a patient with severe rheumatoid polyarthritis: case report. Int $J$ Oral Maxillofac Implants 2011; 26: e19-22.

49. Weinlander M, Krennmair G, Piehslinger E. Implant prosthodontic rehabilitation of patients with rheumatic disorders: a case series report. Int J Prosthodont 2010; 23: 22-28.

50. Krennmair G, Seemann R, Piehslinger E. Dental implants in patients with rheumatoid arthritis: clinical outcome and peri-implant findings. J Clin Periodontol 2010; 37: 928-936.

51. Wild S, Roglic G, Green A, Sicree R, King H. Global prevalence of diabetes: estimates for the year 2000 and projections for 2030. Diabetes Care 2004 27: 1047-1053.

52. Retzepi M, Donos N. The effect of diabetes mellitus on osseous healing. Clin Oral Implants Res 2010; 21: 673-681.

53. Mellado-Valero A, Ferrer Garcia J C, Herrera Ballester A, Labaig Rueda C. Effects of diabetes on the osseointegration of dental implants. Med Oral Patol Oral Cir Bucal 2007; 12: E38-43.

54. Kotsovilis S, Karoussis I K, Fourmousis I. A comprehensive and critical review of dental implant placement in diabetic animals and patients. Clin Oral Implants Res 2006; 17: 587-599.

55. Retzepi M, Lewis M P, Donos N. Effect of diabetes and metabolic control on de novo bone formation following guided bone regeneration. Clin Oral Implants Res 2010; 21: 71-79.

56. Dubey R K, Gupta D K, Singh A K. Dental implant survival in diabetic patients; review and recommendations. Nat/ J Maxillofac Surg. 2013; 4: 142-150.

57. Olson J W, Shernoff A F, Tarlow J L, Colwell J A, Scheetz J P, Bingham S F. Dental endosseous implan assessments in a type 2 diabetic population: a prospective study. Int J Oral Maxillofac Implants 2000; 15: $811-818$

58. Fiorellini J P, Chen P K, Nevins M, Nevins ML. A retrospective study of dental implants in diabetic patients. Int J Periodontics Restorative Dent 2000; 20: 366-373.

59. Smith R A, Berger R, Dodson T B. Risk factors associated with dental implants in healthy and medically compromised patients. Int J Oral Maxillofac Implants 1992; 7: 367-372.

60. Ferreira S D, Silva G L M, Cortelli J R, Costa J E, Costa $F 0$. Prevalence and risk variables for peri-implant disease in Brazilian subjects. J Clin Periodonto/ 2006; 33: 929-935.

61. Javed $F$, Romanos $G$ E. Impact of diabetes mellitus and glycaemic control on the osseointegration of dental implants: a systematic literature review. J Periodontol 2009; 80: 1719-1730.

62. Oates T W, Huynh-Ba G, Vargas A, Alexander P, Feine $J$. A critical review of diabetes, glycaemic control, and dental implant therapy. Clin Oral Implants Res 2013; 24: 117-127.

63. Dowell S, Oates T W, Robinson M. Implant success in people with type 2 diabetes mellitus with varying glycaemic control: a pilot study. J Am Dent Assoc 2007: 138: 355-361.

64. Turkyilmaz I. One-year clinical outcome of dental implants placed in patients with type 2 diabetes mellitus: a case series. Implant Dent 2010; 19: 323-329.

65. Tawil G, Younan R, Azar P, Sleilati G. Conventional and advanced implant treatment in the type II diabetic patient: surgical protocol and long-term clinical results. Int J Oral Maxillofac Implants 2008; 23: 744-752.

66. Marchand F, Raskin A, Dionnes-Hornes A et al. Dental implants and diabetes: conditions for success. Diabetes Metab 2012; 38: 14-19.

67. Courtney M W, Jr., Snider T N, Cottrell D A. Dental implant placement in type II diabetics: a review of the literature. J Mass Dent Soc 2010; 59: 12-14.

68. Anner $R$, Grossmann $Y$, Anner $Y$, Levin L. Smoking, diabetes mellitus, periodontitis, and supportive periodontal treatment as factors associated with dental implant survival: a long-term retrospective evaluation of patients followed for up to 10 years. Implant Dent 2010; 19: 57-64. 
69. Hwang D, Wang H L. Medical contraindications to implant therapy: Part II: Relative contraindications. Implant Dent 2007: 16: 13-23.

70. Moy P K, Medina D, Shetty V, Aghaloo T L. Dental implant failure rates and associated risk factors. Int $J$ Oral Maxillofac Implants 2005; 20: 569-577.

71. Khadivi V, Anderson J, Zarb G A. Cardiovascular disease and treatment outcomes with osseointegration surgery. J Prosthet Dent 1999; 81: 533-536.

72. Taguchi T, Fukuda K, Sekine H, Kakizawa T. Intravenous sedation and haemodynamic changes during dental implant surgery. Int J Oral Maxillofac Implants 2011: 26: 1303-1308.

73. Farbod F, Kanaan H, Farbod J. Infective endocarditis and antibiotic prophylaxis before dental/oral procedures: latest revision to the guidelines by the American Heart Association published April 2007. Int J Oral Maxillofac Surg 2009; 38: 626-631.

74. Mannucci P M, Tuddenham E G. The hemophilias - from royal genes to gene therapy. N Engl J Med 2001; 344: 1773-1779.

75. Totonchi A, Eshraghi Y, Beck D, McCrae K, Guyuron B. Von Willebrand disease: screening, diagnosis, and management. Aesthet Surg J 2008; 28: 189-194.

76. Anderson J A, Brewer A, Creagh D et al. Guidance on the dental management of patients with haemophilia and congenital bleeding disorders. Br Dent J 2013; 215: 497-504.

77. Hewson I D, Daly J, Hallett K B et al. Consensus statement by hospital based dentists providing dental treatment for patients with inherited bleeding disorders. Aust Dent J 2011; 56: 221-226.

78. Madrid C, Sanz M. What influence do anticoagulants have on oral implant therapy? A systematic review. Clin Oral Implants Res 2009; 20 Suppl 4: 96-106.

79. Chong E, Kalia V, Willsie S, Winkle P. Drug-drug interactions between sucroferric oxyhydroxide and losartan, furosemide, omeprazole, digoxin and warfarin in healthy subjects. J Nephrol 2014 [Epub ahead of print].

80. Wynn R L. Bleeding risks for older patients taking warfarin and commonly prescribed antibiotics and antifungals simultaneously. Gen Dent 2012; 60: 454-456.

81. Kim K Y, Epplen K, Foruhari F, Alexandropoulos H. Update on the interaction of rifampin and warfarin. Prog Cardiovasc Nurs 2007; 22: 97-100.

82. Rice P J, Perry R J, Afzal Z, Stockley I H. Antibacterial prescribing and warfarin: a review. Br Dent J. 2003; 194: 411-415.

83. Zhang $K$, Young $C$, Berger J. Administrative claims analysis of the relationship between warfarin use and risk of haemorrhage including drug-drug and drug-disease interactions. J Manag Care Pharm. 2006; 12: 640-648.

84. Rasool S, Ali A, Bashir F. Oral lichen planus. J Coll Physicians Surg Pak 2007; 17: 764-765.

85. Edwards P C, Kelsch R. Oral lichen planus: clinical presentation and management. J Can Dent Assoc 2002; 68: 494-499.

86. Esposito S J, Camisa C, Morgan M. Implant retained overdentures for two patients with severe lichen planus: a clinical report. J Prosthet Dent 2003; 89: 6-10.

87. Reichart P A. Oral lichen planus and dental implants. Report of three cases. Int J Oral Maxillofac Surg 2006: 35: 237-240.

88. Czerninski R, Eliezer M, Wilensky A, Soskolne A. Oral lichen planus and dental implants - a retrospective study. Clin Implant Dent Relat Res 2013; 15: 234-242.

89. Hernandez G, Lopez-Pintor R M, Arriba L, Torres J, de Vicente J C. Implant treatment in patients with oral lichen planus: a prospective-controlled study. Clin Oral Implants Res 2012; 23: 726-732.

90. Fitzpatrick S G, Hirsch S A, Gordon S C. The malignant transformation of oral lichen planus and oral lichenoid lesions: a systematic review. J Am Dent Assoc 2014; 145: 45-56.

91. Mehta U, Brunworth J, Fete T J, Sindwani R. Head and neck manifestations and quality of life of patients with ectodermal dysplasia. Otolaryngol Head Neck Surg. 2007; 136: 843-847.

92. Bergendal B. Orodental manifestations in ectodermal dysplasia - a review. Am J Med Genet A. 2014; doi: 10.1002/ajmg.a.36571 [Epub ahead of print].

93. Candel-Marti M E, Ata-Ali J, Penarrocha-Oltra D, Penarrocha-Diago M, Bagan J V. Dental implants in patients with oral mucosal alterations: an update. Med Oral Patol Oral Cir Bucal 2011; 16: e787-793.

94. Yap A K, Klineberg I. Dental implants in patients with ectodermal dysplasia and tooth agenesis: a critical review of the literature. Int J Prosthodont 2009; 22: 268-276.

95. Klineberg I, Cameron A, Hobkirk J et al. Rehabilitation of children with ectodermal dysplasia. Part 2: an international consensus meeting. Int J Oral Maxillofac Implants 2013; 28: 1101-1109.

96. Ahmadian L, Monzavi A, Arbabi R, Hashemi H M. Fullmouth rehabilitation of an edentulous patient with Papillon-Lefevre syndrome using dental implants: a clinical report. J Prosthodont 2011; 20: 643-648.

97. Al Farraj, AlDosari A. Oral rehabilitation of a case of Papillon-Lefevre syndrome with dental implants. Saudi Med J 2013: 34: 424-427.

98. Senel F C, Altintas N Y, Bagis B et al. A 3year follow-up of the rehabilitation of Papillon-Lefevre syndrome by dental implants. J Oral Maxillofac Surg 2012; 70: 163-167.

99. Fine J D. Inherited epidermolysis bullosa. Orphanet J Rare Dis 2010; 5: 12

100. Penarrocha M, Larrazabal C, Balaguer J, Serrano C, Silvestre J, Bagan J V. Restoration with implants in patients with recessive dystrophic epidermolysis bullosa and patient satisfaction with the implantsupported superstructure. Int J Oral Maxillofac Implants 2007; 22: 651-655.

101. Feijoo J F, Bugallo J, Limeres J, Penarrocha D, Penarrocha M, Diz P. Inherited epidermolysis bullosa: an update and suggested dental care considerations. J Am Dent Assoc 2011; 142: 1017-1025.

102. Penarrocha-Diago M, Serrano C, Sanchis J M, Silvestre F J, Bagan J V. Placement of endosseous implants in patients with oral epidermolysis bullosa. Oral Surg Oral Med Oral Pathol Oral Radiol Endod 2000; 90: 587-590.

103. Lee H, Al Mardini M, Ercoli C, Smith M N. Oral rehabilitation of a completely edentulous epidermolysis bullosa patient with an implant-supported prosthesis: a clinical report. J Prosthet Dent 2007; 97: 65-69.

104. Muller F, Bergendal B, Wahlmann U, Wagner W. Implant-supported fixed dental prostheses in an edentulous patient with dystrophic epidermolysis bullosa. Int J Prosthodont 2010; 23: 42-48.

105. Siqueira M A, de Souza Silva J, Silva F W, DiazSerrano K V, Freitas A C, Queiroz A M. Dental treatment in a patient with epidermolysis bullosa. Spec Care Dentist 2008; 28: 92-95.

106. Kim D D, Ghali G E. Dental implants in oral cancer reconstruction. Dent Clin North Am. 2011; 55: 871-882.

107. Harding S A, Hodder S C, Courtney D J, Bryson P J. Impact of perioperative hyperbaric oxygen therapy on the quality of life of maxillofacial patients who undergo surgery in irradiated fields. Int J Oral Maxillofac Surg 2008; 37: 617-624.

108. Koga D H, Salvajoli J V, Alves F A. Dental extractions and radiotherapy in head and neck oncology: review of the literature. Oral Dis 2008; 14: 40-44.

109. Zheng M, Li L, Tang Y, Liang X H. How to improve the survival rate of implants after radiotherapy for head and neck cancer? J Periodontal Implant Sci 2014; 44: $2-7$.

110. Inde S, Kopp S, Gundlach K, Konstantinovic V S. Effects of radiation therapy on craniofacial and dental implants: a review of the literature. Oral Surg Oral Med Oral Pathol Oral Radiol Endod. 2009; 107: 56-65.

111. Chambrone L, Mandia J, Jr., Shibli J A, Romito G A, Abrahao M. Dental implants installed in irradiated jaws: a systematic review. J Dent Res. 2013; 92(12 Suppl): 119S-130S

112. Granstrom G, Jacobsson M, Tjellstrom A. Titanium implants in irradiated tissue: benefits from hyperbaric oxygen. Int J Oral Maxillofac Implants 1992; 7: $15-25$.

113. Granstrom G, Tjellstrom A, Branemark P I. Osseointegrated implants in irradiated bone: a casecontrolled study using adjunctive hyperbaric oxygen therapy. J Oral Maxillofac Surg 1999; 57: 493-499.

114. Teguh D N, Levendag P C, Noever I et al. Early hyperbaric oxygen therapy for reducing radiotherapy side effects: early results of a randomized trial in oropharyngeal and nasopharyngeal cancer. Int $J$ Radiat Oncol Biol Phys 2009; 75: 711-716.

115. Esposito M, Worthington H V. Interventions for replacing missing teeth: hyperbaric oxygen therapy for irradiated patients who require dental implants. Cochrane Database Syst Rev 2013; 9: CD003603.

116. Granstrom G. Radiotherapy, osseointegration and hyperbaric oxygen therapy. Periodontol 2000; 2003: 33: $145-162$

117. Karr R A, Kramer D C, Toth B B. Dental implants and chemotherapy complications. J Prosthet Dent 1992; 67: 683-687.

118. Kovacs A F. Influence of chemotherapy on endostea implant survival and success in oral cancer patients. Int J Oral Maxillofac Surg 2001; 30: 144-147.

119. Baron M, Gritsch F, Hansy A M, Haas R. Implants in an HIV-positive patient: a case report. Int J Oral Maxillofac Implants 2004; 19: 425-430.

120. Rajnay Z W, Hochstetter R L. Immediate placement of an endosseous root-form implant in an HIVpositive patient: report of a case. J Periodontol 1998; 69: $1167-1171$

121. Stevenson G C, Riano P C, Moretti A J, Nichols C M, Engelmeier R L, Flaitz C M. Short-term success of osseointegrated dental implants in HIV-positive individuals: a prospective study. J Contemp Dent Pract. 2007; 8: 1-10.

122. Kolhatkar S, Khalid S, Rolecki A, Bhola M, Winkler $\mathrm{J}$ R. Immediate dental implant placement in HIVpositive patients receiving highly active antiretroviral therapy: a report of two cases and a review of the literature of implants placed in HIV-positive individuals. J Periodontol 2011; 82: 505-511.

123. Strietzel FP, Rothe S, Reichart P A, SchmidtWesthausen A M. Implant-prosthetic treatment in HIV-infected patients receiving highly active antiretroviral therapy: report of cases. Int J Oral Maxillofac Implants 2006: 21: 951-956.

124. Oliveira M A, Gallottini M, Pallos D, Maluf PS, Jablonka F, Ortega K L. The success of endosseous implants in human immunodeficiency virus-positive patients receiving antiretroviral therapy: a pilot study. J Am Dent Assoc 2011; 142: 1010-1016.

125. Sakakura C E, Margonar R, Holzhausen M, Nociti F H, Jr., Alba R C, Jr., Marcantonio E, Jr. Influence of cyclosporin A therapy on bone healing around titanium implants: a histometric and biomechanic study in rabbits. J Periodonto/ 2003; 74: 976-981.

126. Sakakura C E, Margonar R, Sartori R, Morais J A Marcantonio $E_{1} J$ J. The influence of cyclosporin a on mechanical retention of dental implants previously integrated to the bone: a study in rabbits. J Periodontol 2006; 77: 2059-2062.

127. Sakakura C E, Marcantonio E, Jr., Wenzel A, Scaf G. Influence of cyclosporin $A$ on quality of bone around integrated dental implants: a radiographic study in rabbits. Clin Oral Implants Res. 2007; 18: 34-39.

128. Duarte P M, Nogueira Filho G R, Sallum E A, de Toledo S, Sallum A W, Nociti Junior F H. The effect of an immunosuppressive therapy and its withdrawal on bone healing around titanium implants. A histometric study in rabbits. J Periodonto/ 2001; 72: 1391-1397.

129. Gu L, Wang O, Yu Y C. Eleven dental implants placed in a liver transplantation patient: a case report and 5-year clinical evaluation. Chin Med J (Engl) 2011; 124: 472-475.

130. Gu L, Yu Y C. Clinical outcome of dental implants placed in liver transplant recipients after 3 years: a case series. Transplant Proc 2011; 43: 2678-2682.

131. Heckmann S M, Heckmann J G, Linke J J, Hohenberge W, Mombelli A. Implant therapy following liver transplantation: clinical and microbiological results after 10 years. J Periodontol 2004; 75: 909-913.

132. Ami S, Wolff A. Implant-supported electrostimulating device to treat xerostomia: a preliminary study. Clin Implant Dent Relat Res 2010; 12: 62-71.

133. Payne A G, Lownie J F, Van Der Linden W J. Implantsupported prostheses in patients with Sjögren's syndrome: a clinical report on three patients. Int J Oral Maxillofac Implants 1997; 12: 679-685.

134. Isidor F, Brøndum K, Hansen H J, Jensen J, SindetPaedersen S. Outcome of treatment with implantretained dental prostheses in patients with Sjögren syndrome. Int J Oral Maxillofac Implants 1999; 14: 736-743.

135. Binon P P. Thirteen-year follow-up of a mandibular implant-supported fixed complete denture in a patient with Sjögren's syndrome: a clinical report. J Prosthet Dent 2005; 94: 409-413. 